\title{
IRAK4 and TLR3 sequence variants may alter breast cancer risk among African-American women
}

\section{Susan T. Yeyeodu ${ }^{1+}$, LaCreis R. Kidd ${ }^{2 \dagger}$, Gabriela M. Oprea-llies ${ }^{3}$, Brian G. Burns ${ }^{3}$, Tiva T. VanCleave ${ }^{2}$, Joong-Youn Shim ${ }^{1}$ and K. Sean Kimbro ${ }^{1}{ }^{*}$}

' Department of Biology, Julius L. Chambers Biomedical/Biotechnology Research Institute, North Carolina Central University, Durham, NC, USA

${ }^{2}$ Department of Pharmacology and Toxicology, University of Louisville, Louisville, KY, USA

${ }^{3}$ Winship Cancer Institute, Emory School of Medicine, Emory University, Atlanta, GA, USA

\section{Edited by:}

Claudia Kemper, King's College

London, UK

\section{Reviewed by:}

Claudia Kemper, King's College London, UK

Janos G. Filep, University of

Montreal, Canada

${ }^{*}$ Correspondence:

K. Sean Kimbro, Department of Biology, Julius L. Chambers

Biomedical/Biotechnology Research Institute, North Carolina Central

University, 700 George Street,

Durham, NC 27707, USA

e-mail:kkimbro@nccu.edu

${ }^{+}$Susan T. Yeyeodu and LaCreis R. Kidd have contributed equally to this work.
Mounting evidence suggests that imbalances in immune regulation contribute to cell transformation. Women of African descent are an understudied group at high risk for developing aggressive breast cancer ( $\mathrm{BrCa}$ ). Therefore, we examined the role of 16 innate immune single nucleotide polymorphisms (SNPs) in relation to $\mathrm{BrCa}$ susceptibility among 174 African-American women in Atlanta, GA, USA. SNPs were examined in germ-line DNA collected from $102 \mathrm{BrCa}$ patients and 72 women with benign nodules using SNPstream methodology. Inheritance of the TLR3 rs 10025405 GG genotype was associated with an $82 \%$ decrease in $\mathrm{BrCa}$ risk. In contrast, individuals who possessed at least one IRAK4 rs4251545 T allele had a 1.68- to 4.99-fold increase in the risk of developing $\mathrm{BrCa}$ relative to those with the referent genotype (OR $=4.99 ; 95 \% \mathrm{Cl}=1.00,25.00 ; p=0.0605)$. However, the IRAK4 rs4251545 locus was only significant under the additive genetic model ( $p$ trend $=0.0406$ ). In silico predictions suggest IRAK4 rs4251545 SNP falls within a transcription enhancer/silencer region of the gene and codes for an Ala428Thr amino acid change. This missense mutation introduces a potential phosphorylation site in the extreme carboxy terminus (XCT) of the IRAK4 kinase domain. Preliminary molecular modeling predicts that this SNP stabilizes two alpha helices within the XCT on the surface of the IRAK4 kinase domain and increases the size of the groove between them. Our in silico results, combined with previous reports noting the presence of IRAK4 and XCT fragments in mouse and human serum, suggest the possibility that the XCT subdomain of IRAK4 possesses biological function. These findings require further evaluation and validation in larger populations, additional molecular modeling as well as functional studies to explore the role of IRAK4 and its XCT in cell transformation and innate immunity.

Keywords: breast cancer, innate immunity, single nucleotide polymorphism, TLR3, IRAK4, African-American, XCT subdomain, extracellular kinase

\section{INTRODUCTION}

Breast cancer $(\mathrm{BrCa})$ is the most common cancer morbidity among women worldwide and is especially prevalent in the US and other developed countries. Several factors contribute to BrCa risk, including age, family history of $\mathrm{BrCa}$, personal history of benign breast disease, late menopause, obesity, high endogenous estrogen and testosterone levels, adult weight gain, early menarche and null parity, and BRCA 1/2 mutations. Specific mutations in BRCA1 and $B R C A 2$ are associated with a genetic predisposition to $\mathrm{BrCa}$. However, these mutations account for only $5-10 \%$ of the reported $\mathrm{BrCa}$ cases (1). Exploring the contribution of other genetic factors associated with $\mathrm{BrCa}$ is an active area of research (2). In

Abbreviations: BrCa, breast cancer; CHARMM22, Chemistry at HARvard Macromolecular Mechanics 22; CI, confidence interval; IRAK4, interleukin-1 receptorassociated kinase 4 gene; IRAK4, interleukin-1 receptor-associated kinase 4 protein; NAMD, not (just) another molecular dynamics simulation software; OR, odds ratio; SNP, single nucleotide polymorphism; TIP3, 3-site rigid water model; TLR, toll-like receptor; $\mathrm{XCT}$, extreme carboxy terminus. fact, compelling evidence has emerged that suggests genetic anomalies in inflammatory and immune response pathways may lead to cellular transformation and contribute to $\mathrm{BrCa}$ pathogenesis $(3,4)$.

Innate immune capabilities enable most tissues, including breast epithelia, to mount a first response to infection through several surface and intracellular membrane receptors (5). Best characterized among these are the Toll-like receptors (TLRs) that recognize pathogens, dietary or environmental toxins, or endogenous biomolecules that possess specific pathogen-associated molecular patterns (PAMPs) or damage-associated molecular patterns (DAMPs). TLRs are triggered as homo- or hetero-dimers and complex with adaptor molecules that recruit regulatory kinases to initiate downstream cellular responses, as summarized in Figure 1. Among these regulatory kinases, IL-1 receptor-associated kinase 4 (IRAK4) is widely employed, and transduces signals from TLRs 1 through 10.

Recent evidence links TLRs and their signaling pathways with tumor progression (6-9). Enhanced TLR expression at the cell surface and in endosomes has been observed in several human 


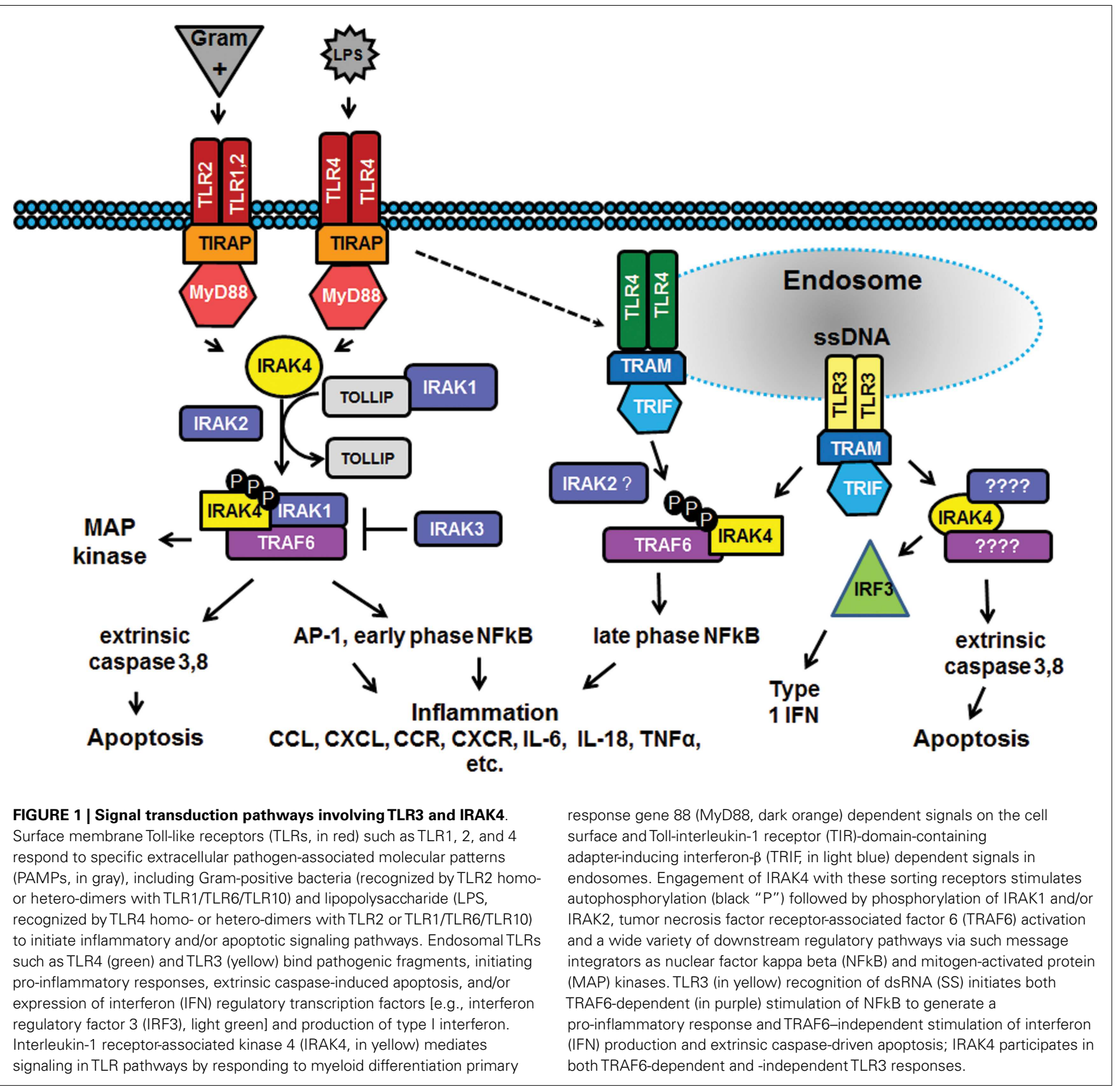

cancers, including $\mathrm{BrCa}(10,11)$. Total and surface expression of TLR2 are both enhanced in the highly metastatic MDA-MB-231 human BrCa cell line relative to the less aggressive MDA-MB-468 or untransformed MCF10A cell lines (12). Further, bacterial peptidoglycan stimulation of TLR2 promotes BrCa invasiveness (12). Consistent with these results, TLR4 knockdown in MDA-MB-231 cells inhibits cell proliferation and inflammatory cytokine secretion (13). Conversely, treatment of MCF7 human BrCa cells with agonists to TLR3 and TLR7 (both located in intracellular endosomes) inhibits $\mathrm{BrCa}$ cell growth that is reversible by treatment with the autophagy inhibitor 3-methyladenine (14). Similarly, activation of TLR5 by flagellin inhibits the growth of MCF7 and
MDA-MB-468 BrCa cell lines (15) and activation of endosomal TLR9 with agonist oligo $(\mathrm{CpG})$ inhibits estrogen-induced growth of MCF7 cells (16). While the precise mechanisms are poorly understood, these findings suggest that anomalies in TLR signaling pathways influence BrCa progression.

Consistent with this, TLR-related sequence variants have been implicated in BrCa susceptibility. Only a few population-based studies have detected single nucleotide polymorphisms (SNPs) in genes related to TLR signaling that alter BrCa risk. Among Korean women, a modest increase in BrCa risk $(\mathrm{OR}=1.63$; $95 \%$ $\mathrm{CI}=1.14,2.34)$ was linked with possession of one or more of the IRAK3 rs1732877 minor alleles (17). Similarly, presence of the 
minor variant of the non-synonymous TLR4 rs4986790 A/G SNP, in which aspartic acid 299 is replaced by glycine, was associated with a modest increase in BrCa risk $(\mathrm{OR}=1.81 ; 95 \% \mathrm{CI}=1.23$, 2.66) in a Greek cohort (18). Finally, inheritance of the homozygous minor variant of the TLR1/TLR6/TLR10 rs7696175 locus (situated in proximity to all three TLR promoters) was associated with a large fourfold increase in $\mathrm{BrCa}$ risk $(\mathrm{OR}=4.11 ; 95 \%$ $\mathrm{CI}=1.28,13.24)$ among African-American women as opposed to little or no risk among women of European ancestry $(\mathrm{OR}=1.20$; $95 \% \mathrm{CI}=0.93,1.53)(19)$. Only the last of these studies addressed BrCa risk among women of African descent, despite the fact that this sub-group suffers disproportionately from more aggressive forms of $\mathrm{BrCa}(20,21)$ and is underrepresented in $\mathrm{BrCa}$ research efforts (22).

The study of the biological/genetic factors that contribute to disparities in $\mathrm{BrCa}$ risk and severity among women of various races is a nascent science, and to date has focused most heavily on differences in hormone receptor expression (2). BarnholtzSloan et al. (19) explored a large panel of SNPs from genes with a variety of functions that had been previously reported as $\mathrm{BrCa}$ susceptibility genes in genome wide association (GWAS) studies (19). Notably, the minor allele frequency of the TLR1/TLR6/TLR10 rs7696175 allele in the Barnholtz-Sloan study is highly disparate between women of African and European descent (3 and 44\%, respectively). Consequently, we selected additional TLR-pathway associated SNPs, in part, based on significant disparities in minor allele frequency ( $\geq 10 \%$ difference) between individuals of African and European descent (Table 1). In the current study, we evaluated 16 TLR-associated SNPs in relation to BrCa among 174 African-American female participants (102 BrCa cases, 72 benign controls).

\section{MATERIALS AND METHODS \\ STUDY POPULATION AND TUMOR CHARACTERIZATION}

Study participants, including 102 BrCa cases and 72 benign controls were enrolled from Grady Memorial Hospital and Emory Midtown Hospital in Atlanta, GA, USA. All participants selfidentified as African-Americans and provided written informed consent for participation in genetic analysis studies under protocol \#20417 approved by Emory University's Institutional Review Board. Socioeconomic status, nutrition, environmental exposure, and other confounding factors were not addressed. Tumor size was measured and tumor stage and invasiveness/morphology were determined according to standard histopathological definitions. Estrogen (ER) and progesterone receptor (PR) and Her2 neu expression were determined by immunohistochemistry staining (23).

\section{CRITERIA FOR TLR SIGNALING GENE AND SNP SELECTION}

Toll-like receptor-associated genes and SNPs were selected using one or more of the following criteria: (1) epidemiological or molecular biological evidence from published reports indicating a relationship between the $\mathrm{SNP} /$ gene with cancer or inflammatory/immune response related diseases (Figure 1); (2) commonly studied loci; (3) marked disparities in genotype frequency comparing women of African descent to their Caucasian counterparts (i.e., $\pm 10 \%$ change) (Table 1); (4) evidence demonstrating a link with alterations in mRNA expression/stability or protein expression/structure or function using in silico tools or published reports ${ }^{1}$; and (5) a minor allele frequency $\geq 1 \%$ reported in the National Center for Biotechnology Information (NCBI) Entrez SNP $(24)^{2}$. The current study focused on 16 SNPs detected in 10 TLR genes as well as downstream markers associated with TLR mediated signaling pathways (i.e., TLR1-4, CD14, IRAK2ঞ4, IRF3, TICAM1, TOLLIP), as described in Table 1.

\section{SNPSTREAM GENOTYPING}

Sixteen candidate SNPs among African-American subjects were genotyped using the GenomeLab ${ }^{\mathrm{TM}}$ SNPstream ${ }^{\circledR}$ Genotyping System (Beckman Coulter, Brea, CA, USA) within the Center for Medical Genomics at Emory University. SNPstream executes highthroughput multiplex genotyping using single-base fluorescent primer extension. Primers were designed using autoprimer tools ${ }^{3}$. Following primer design, allelic discrimination was facilitated, in part, by PCR amplification of 100 base pairs flanking each SNP using 384-well PCR plates. GenomeLabSNPstream Genotyping System Software Suite v2.3 was used for image processing and genotype base calling.

\section{STATISTICAL ANALYSIS}

Logistic regression (LR) analysis was used to evaluate innate immunity associated SNPs among African-Americans in relation to BrCa risk. To assess whether individuals possessing innate immune sequence variants influence the risk of developing $\mathrm{BrCa}$, we tested for significant differences in the distribution of homozygous major, heterozygous, or homozygous minor genotypes between cases and controls using the chi-square test of homogeneity. The associations between BrCa risk and selected polymorphic genes, expressed as odds ratios (ORs) and corresponding 95\% confidence intervals (CIs), were estimated using unconditional multivariate LR models. Risk estimates were adjusted for age. LR analyses for genetic variants and $\mathrm{BrCa}$ development were conducted using the major/common genotype as the reference group. All chi-square and LR analyses were conducted using SAS 9.1.3 (SAS Institute, Cary, NC, USA). Statistical significance required a $P$-value $<0.05$.

\section{MOLECULAR MODELING}

Molecular dynamics (MD) simulations were performed to examine the effect of the IRAK4 rs4251545 Ala428Thr variant on enzyme structure, as described previously (25), as described previously. Briefly, simulations were performed with NAMD parallel, object-oriented high-performance software (ver. 2.6b2 for LinuxPower-MPI). CHARMM22 force field parameters were used for the protein along with the three-site TIP3 rigid water model. Initial coordinates of IRAK4 were obtained from the $\mathrm{x}$-ray structure of the human IRAK4 kinase domain from amino acids 160-460 (PDB code: 2OIB) (26). A model of the IRAK4 rs4251545 variant was generated by replacing Ala428 in IRAK4 with a Thr residue. After immersion of IRAK4 in a rectangular cell of water molecules

\footnotetext{
${ }^{1}$ http://snpinfo.niehs.nih.gov/snpinfo/snpfunc.htm

${ }^{2}$ www.ncbi.nlm.nih.gov

${ }^{3}$ http://www.autoprimer.com
} 
Table 1 | Prevalence of selected innate immunity sequence variants and their functional consequence.

\begin{tabular}{|c|c|c|c|c|c|c|c|c|c|c|c|}
\hline dbSNP ID & Gene & $\begin{array}{l}\text { NT } \\
\text { change }\end{array}$ & $\begin{array}{l}\text { MAF } \\
\text { AA (\%) }\end{array}$ & $\begin{array}{l}\text { Major/ } \\
\text { major } \\
\text { genotype } \\
n(\%) \text { AA }\end{array}$ & $\begin{array}{l}\text { Major/ } \\
\text { minor } \\
\text { genotype } \\
n(\%) \text { AA }\end{array}$ & $\begin{array}{l}\text { Minor/ } \\
\text { minor } \\
\text { genotype } \\
n(\%) \text { AA }\end{array}$ & $\begin{array}{l}\text { MAF } \\
\text { Cau } \\
(\%)\end{array}$ & $\begin{array}{l}\text { Major/ } \\
\text { major } \\
\text { genotype } \\
n(\%) \text { Cau }\end{array}$ & $\begin{array}{l}\text { Major/ } \\
\text { minor } \\
\text { genotype } \\
n(\%) \text { Cau }\end{array}$ & $\begin{array}{l}\text { Minor/ } \\
\text { minor } \\
\text { genotype } \\
n(\%) \text { Cau }\end{array}$ & $\begin{array}{l}P \text {-value } \\
\text { AA vs. } \\
\text { Cau }\end{array}$ \\
\hline rs10025405 & TLR3 & $A>G$ & $\mathrm{G}=31.6$ & $24(49.0)$ & 19 (38.8) & $6(12.2)$ & $\mathrm{G}=42.0$ & 39 (34.5) & 53 (46.9) & 21 (18.6) & 0.205 \\
\hline rs10759930 & TLR4 & $\mathrm{C}>\mathrm{T}$ & $\mathrm{T}=8.7$ & 19 (82.6) & $4(17.4)$ & $0(0.0)$ & $\mathrm{T}=41.7$ & $7(29.2)$ & $14(58.3)$ & $3(12.5)$ & 0.0006 \\
\hline rs11672931 & $\begin{array}{l}\text { TICAM1 } \\
\text { (aka TRIF) }\end{array}$ & & $\mathrm{G}=23.8$ & 12 (57.1) & $8(38.1)$ & $1(4.8)$ & $\mathrm{G}=27.3$ & $13(59.1)$ & $6(27.3)$ & 3 (13.6) & 0.606 \\
\hline rs242724 & IRAK2 & $A>C$ & $C=22.7$ & $6(54.5)$ & $5(45.5)$ & $0(0.0)$ & $C=31.0$ & 56 (49.6) & 44 (38.9) & 13 (11.5) & 0.735 \\
\hline rs2569188 & CD14 & $A>G$ & $\begin{aligned} G & =39.8 \\
A & =60.2\end{aligned}$ & $18(36.7)$ & 23 (46.9) & 8 (16.3) & $A=49.1$ & $24(21.4)$ & $62(55.4)$ & $26(23.2)$ & 0.118 \\
\hline rs4251545 & IRAK4 & $G>A$ & $A=32.6$ & 11 (47.8) & $9(39.1)$ & $3(13.0)$ & $A=10.4$ & $19(79.2)$ & $5(20.8)$ & $0(0.0)$ & 0.036 \\
\hline rs4684672 & IRAK2 & $\mathrm{G}>\mathrm{A}$ & $A=22.7$ & 14 (63.6) & $6(27.3)$ & $2(9.1)$ & $A=39.5$ & 7 (36.8) & $9(47.4)$ & $3(15.8)$ & 0.224 \\
\hline rs4696480 & TLR2 & $\mathrm{T}>\mathrm{A}$ & $A=39.6$ & 8 (33.3) & $13(54.2)$ & $3(12.5)$ & $A=46.8$ & $8(25.8)$ & 17 (54.8) & $6(19.4)$ & 0.759 \\
\hline rs4833095 & TLR1 & $\mathrm{C}>\mathrm{T}$ & $\begin{array}{l}T=34.8 \\
C=65.2\end{array}$ & 11 (47.8) & $8(34.8)$ & $4(17.4)$ & $C=20.8$ & $15(62.5)$ & 8 (33.3) & $9(4.2)$ & 0.577 \\
\hline rs4986790 & TLR4 & $A>G$ & $\mathrm{G}=3.3$ & $20(83.3)$ & $4(16.7)$ & $0(0.0)$ & $\mathrm{G}=4.4$ & $29(93.5)$ & $2(6.5)$ & $0(0.0)$ & 0.387 \\
\hline rs5743899 & TOLLIP & $A>G$ & $G=34.8$ & $9(39.1)$ & $12(52.2)$ & $2(8.7)$ & $\mathrm{G}=17.9$ & 75 (67.0) & $34(30.4)$ & $3(2.7)$ & 0.019 \\
\hline rs6442161 & IRAK2 & $\mathrm{C}>\mathrm{T}$ & $\mathrm{T}=21.9$ & $30(62.5)$ & $15(31.2)$ & $3(6.2)$ & $\mathrm{T}=42.5$ & 41 (36.3) & $48(42.5)$ & $24(21.2)$ & 0.00400 \\
\hline rs7251 & IRF3 & $C>G$ & $\begin{array}{l}G=25.0 \\
C=75.0\end{array}$ & $14(58.3)$ & 8 (33.3) & $2(8.4)$ & $C=37.1$ & $21(36.2)$ & $31(53.4)$ & $6(10.3)$ & 0.205 \\
\hline rs7045953 & TLR4 & $A>G$ & $\mathrm{G}=17.4$ & $15(65.2)$ & 8 (34.8) & $0(0.0)$ & $G=14.6$ & $80(70.8)$ & $33(29.2)$ & $0(0.0)$ & 0.623 \\
\hline rs7657186 & TLR3 & $G>A$ & $A=25.0$ & $13(54.2)$ & $10(41.7)$ & $1(4.2)$ & $A=24.5$ & $18(60.0)$ & $9(30.0)$ & $3(10.0)$ & 0.578 \\
\hline rs913930 & TLR4 & $A>G$ & $G=28.3$ & $14(60.9)$ & $5(21.7)$ & $4(17.4)$ & $G=38.1$ & $48(42.5)$ & 44 (38.9) & 21 (18.6) & 0.198 \\
\hline
\end{tabular}

MAF, minor allele frequency; AA, African-American/African Ancestry; Cau, Caucasian;

${ }^{a}$ The Fisher's Exact test or chi-square test of homogeneity was used to compare the genotype frequencies from women of African and European descent using data from NCBI.

to produce a periodic box of dimension $93 \AA \times 89 \AA \times 96 \AA$, the variant enzyme system was subjected to 2,500 steps of minimization. The minimized structure was then simulated for $5 \mathrm{~ns}$ in a constant temperature and pressure ensemble. The temperature was maintained at $310^{\circ} \mathrm{K}$ through the use of Langevin dynamics with a damping coefficient of $1 / p s$. The pressure was maintained at one ATM by using the Nosé-Hoover method. The van der Waals interactions were switched at $10 \AA$ and zeroed smoothly at $12 \AA$. Electrostatic interactions were monitored using the Particle Mesh Ewald (PME) method (27). A pair list for calculating the van der Waals and electrostatic interactions was set to $13.5 \AA$ and updated every ten steps. The timestep size for integration of each step of the simulation was $1 \mathrm{fs}$. The resulting variant was compared with the wild-type enzyme structure.

\section{RESULTS}

\section{CHARACTERIZATION OF PATIENTS AND THEIR TUMORS}

The patient and tumor characteristics of our study participants are summarized in Table 2. For this pilot study based in Atlanta,
GA, we enrolled 174 African-American women who had been diagnosed with $\mathrm{BrCa}$ or who possessed benign nodules (control). At enrollment, BrCa patients were approximately 10 years older than women with benign disease $(<0.0001)$; about $66 \%$ of the cases were diagnosed after age 50 . The majority of the breast tumors were characteristic of earlier stages (Stage 0-II) of disease (91.8\%) with invasive pathologies (64.7\%), namely invasive lobular or uninvasive ductal carcinomas. Further, more than half of the cases lacked expression of estrogen receptor (31.6\%), PR (39.8\%), or Her-2 neu (87.3\%), resulting in 29.6 and $22.1 \%$ double or triple negative breast tumors, respectively.

\section{PREVALENCE OF MINOR ALLELES/GENOTYPE FREOUENCY}

The prevalence of the $16 T L R$ variants was fairly common among the women of African descent in our study, based on a minor allele frequency $\geq 5 \%$. With the exception of the functional Ala299Gly TLR4 rs4986790 variant, the minor allele frequencies among controls in our study set ranged between 8.7 and $39.8 \%$, with a median of $22.0 \%$. Approximately $16 \%$ of the women possessed one copy of 
Table 2 | Patient and tumor characteristics.

\begin{tabular}{|c|c|c|c|}
\hline Characteristics & $\begin{array}{l}\text { Cases } \\
n(\%)\end{array}$ & $\begin{array}{l}\text { Controls } \\
n(\%)\end{array}$ & $p$-Value \\
\hline Median age at enrollment (range) & $57(24-89)$ & 47 (18-78) & $<0.0001$ \\
\hline \multicolumn{4}{|l|}{ Age at enrollment (years) } \\
\hline$>70$ & $20(19.6)$ & $6(8.3)$ & 0.0002 \\
\hline $61-70$ & $17(16.7)$ & $5(6.9)$ & \\
\hline $51-60$ & 35 (34.3) & $20(27.8)$ & \\
\hline $41-50$ & $23(22.5)$ & $19(26.4)$ & \\
\hline$\leq 40$ & 7 (6.9) & $22(30.6)$ & \\
\hline \multicolumn{4}{|l|}{ Age at diagnosis (years) } \\
\hline$>70$ & 7 (6.9) & & \\
\hline $61-70$ & $23(22.5)$ & & \\
\hline $51-60$ & 37 (36.3) & & \\
\hline $41-50$ & $16(15.7)$ & & \\
\hline$\leq 40$ & 19 (18.6) & & \\
\hline \multicolumn{4}{|l|}{ Tumor stage } \\
\hline 0 & $35(35.7)$ & & \\
\hline । & $30(30.6)$ & & \\
\hline ॥ & $25(25.5)$ & & \\
\hline III & $3(3.1)$ & & \\
\hline IV & $5(5.1)$ & & \\
\hline Not determined & $4(3.9)$ & & \\
\hline \multicolumn{4}{|l|}{ Tumor size $(\mathrm{cm})$} \\
\hline$<2$ & $53(60.9)$ & & \\
\hline$\geq 2$ & $34(39.1)$ & & \\
\hline Not determined & $15(14.7)$ & & \\
\hline \multicolumn{4}{|l|}{ Nodal status } \\
\hline Negative & $45(68.2)$ & & \\
\hline Positive & $21(31.8)$ & & \\
\hline Not determined & $36(35.3)$ & & \\
\hline \multicolumn{4}{|l|}{ Pathology } \\
\hline Non-invasive (DCIS, LCIS) & $36(35.3)$ & & \\
\hline Invasive (IDC, ILC) & $66(64.7)$ & & \\
\hline Not determined & $0(0.0)$ & & \\
\hline \multicolumn{4}{|l|}{ Estrogen receptor (ER) } \\
\hline Positive & $67(68.4)$ & & \\
\hline Negative & $31(31.6)$ & & \\
\hline Not determined & $4(3.9)$ & & \\
\hline \multicolumn{4}{|l|}{ Progesterone receptor (PR) } \\
\hline Positive & $59(60.2)$ & & \\
\hline Negative & 39 (39.8) & & \\
\hline Not determined & $4(3.9)$ & & \\
\hline \multicolumn{4}{|l|}{ Her-2 neu } \\
\hline Positive & $9(12.7)$ & & \\
\hline Negative & $62(87.3)$ & & \\
\hline Not determined & $31(30.4)$ & & \\
\hline \multicolumn{4}{|l|}{ Triple negative $\mathrm{BrCa}^{\mathrm{a}}$} \\
\hline No & $74(77.9)$ & & \\
\hline Yes & $21(22.1)$ & & \\
\hline Not determined & $7(6.9)$ & & \\
\hline \multicolumn{4}{|l|}{ Double negative $\mathrm{BrCa}^{\mathrm{b}}$} \\
\hline No & $69(70.4)$ & & \\
\hline Yes & $29(29.6)$ & & \\
\hline Not determined & 4 (3.9) & & \\
\hline
\end{tabular}

(Continued)

\begin{tabular}{lcl}
\hline Characteristics & $\begin{array}{l}\text { Cases } \\
\boldsymbol{n}(\%)\end{array}$ & $\begin{array}{l}\text { Controls } \\
\boldsymbol{n}(\%)\end{array}$ \\
\hline Surgery status & & \\
$\quad$ No surgery(biopsy only) & $3(2.9)$ & \\
Lumpectomy & $33(32.4)$ & \\
Partial mastectomy & $25(24.5)$ \\
Total mastectomy & $34(33.3)$ \\
Modified radical mastectomy & $6(5.9)$ \\
Unknown & $1(1.0)$ &
\end{tabular}

${ }^{a} E R-, P R-$, Her2-

${ }^{b} E R-, P R-$

the TLR4 $\mathrm{rs} 4986790 \mathrm{~A} / \mathrm{G}$ genotype, with a minor allele frequency of $3.3 \%$. For 15 out of 16 innate immunity SNPs, there were no significant departures in the observed genotype frequencies among controls when compared with expected frequencies under the Hardy-Weinberg Equilibrium (HWE) [ $p \geq 0.4833]$. Moreover, the prevalence of the genotypes among controls was comparable to those reported for women of African descent in NCBI SNP Entrez ( $p \geq 0.056)$ (24). Only the TICAM1 rs11672931 variant deviated from HWE $(p=0.0027)$, despite the fact that its allele (27.3\%) and genotype frequency among our study participants corroborated with NCBI values (24).

\section{RELATIONSHIP BETWEEN TLR-ASSOCIATED SEOUENCE VARIANTS AND BREAST CANCER RISK}

SNPstream analysis of 16 innate immunity SNPs among AfricanAmerican women with $\mathrm{BrCa}(n=102)$ and benign disease $(n=72)$ identified 4 loci whose genotype frequencies were altered with respect to $\mathrm{BrCa}$ risk (Table 3 ). In the unadjusted models, three of these were associated with a decrease in BrCa risk. Possession of one or more minor TLR2 rs4696480 A, TLR3 rs $10025403 \mathrm{G}$, and IRAK2 rs6442161 T alleles was associated with a $45-79 \%$ reduction in the risk of developing BrCa. Among these three loci, statistical significance was observed only for the TLR3 rs10025403 marker under the unadjusted and/or ageadjusted dominant $(\mathrm{OR}=0.18,95 \% \mathrm{CI}=0.05,0.70) ; p=0.0123)$, recessive $(\mathrm{OR}=0.20,95 \% \mathrm{CI}=0.06,0.75 ; p$-value $=0.0143)$, and additive (unadjusted $p$-value for trend $=0.0337$ ) genetic models.

On the other hand, inheritance of two copies of the IRAK4 rs4251545 TT genotype resulted in a fivefold increase in BrCa susceptibility relative to those with the referent genotype $(\mathrm{OR}=4.99$; $95 \% \mathrm{CI}=1.00,25.00 ; p=0.0605)$; however, the findings were not statistically significant. Notably, under the additive genetic model, we observed a significant "dose-response" between the number of alleles in the genetic model (i.e., $0,1,2$ ) and the risk estimates ( $p$-value for trend $=0.0406)$ for this SNP.

\section{FUNCTIONAL CONSEQUENCES OF TLR3 rs10025405 AND IRAK4 rs4251545}

Inheritance of the homozygous minor TLR3 rs10025405 G allele was associated with reduced BrCa risk. The location of this SNP in the $3^{\prime}$ flanking region of the TLR3 gene may alter mRNA expression or processing with resulting downstream effects on 
Table 3 | Innate immune SNPs associated with BrCa risk among African-American women.

\begin{tabular}{|c|c|c|c|c|c|c|c|c|c|}
\hline Genes & $\begin{array}{l}\text { dbSNP ID location } \\
\text { predicted function }\end{array}$ & Genotype & $\begin{array}{l}\text { Cases } \\
n(\%)\end{array}$ & $\begin{array}{l}\text { Controls } \\
n(\%)\end{array}$ & $\begin{array}{l}\text { NCBI } \\
\text { AA }\end{array}$ & OR (95\% Cl) & Adj OR (95\% Cl) & $p$-Value & $\begin{array}{l}p \text {-Value } \\
\text { for trend }\end{array}$ \\
\hline \multirow[t]{4}{*}{ TLR2 } & rs4696480 & $\mathrm{TT}$ & $47(46.1)$ & 23 (31.9) & 0.33 & 1.00 (reference) & 1.00 (reference) & 0.1357 & 0.1959 \\
\hline & 1685bp from $5^{\prime}$ & AA & $18(17.6)$ & $13(18.1)$ & 0.13 & $0.68(0.28,1.62)$ & $0.53(0.21,1.34)$ & 0.3808 & \\
\hline & & $\geq 1 \mathrm{~A}$ allele & 55 (53.9) & $49(68.1)$ & 0.67 & $0.55(0.29,1.03)$ & $0.55(0.28,1.09)$ & 0.0624 & \\
\hline & & $\bar{A} A$ vs $(T T+T A)$ & & & & $0.97(0.44,2.14)$ & $0.70(0.30,1.65)$ & 0.9446 & \\
\hline \multirow{4}{*}{ TLR3 } & $3 '$ near gene & $A G$ & $44(43.1)$ & $30(41.6)$ & 0.31 & $0.84(0.44,1.59)$ & $0.80(0.40,1.62)$ & 0.5987 & \\
\hline & & GG & $4(3.9)$ & $11(15.3)$ & 0.04 & $0.21(0.06,0.71)$ & $0.18(0.05,0.70)$ & 0.0123 & \\
\hline & & $\geq 1 \mathrm{G}$ allele & $48(47.0)$ & 41 (56.9) & 0.35 & $0.67(0.37,1.23)$ & $0.64(0.33,1.24)$ & 0.1997 & \\
\hline & & $\bar{G}$ vs $(A A+A G)$ & & & & $0.23(0.07,0.74)$ & $0.20(0.06,0.75)$ & 0.0143 & \\
\hline \multirow[t]{2}{*}{ IRAK2 } & rs6442161 & $\mathrm{CC}$ & $56(54.9)$ & $33(45.8)$ & & 1.00 (reference) & 1.00 (reference) & 0.1058 & 0.0721 \\
\hline & & TT vs $(C C+C T)$ & & & & $0.35(0.12,0.99)$ & $0.32(0.10,1.05)$ & 0.0469 & \\
\hline \multirow[t]{5}{*}{ IRAK4 } & rs4251545 & $\mathrm{CC}$ & $50(49.0)$ & $44(62.0)$ & 0.46 & 1.00 (reference) & 1.00 (reference) & 0.0991 & 0.0406 \\
\hline & Exon & $\mathrm{CT}$ & $42(41.2)$ & $25(35.2)$ & 0.39 & $1.51(0.80,2.86)$ & $1.68(0.83,3.40)$ & 0.2042 & \\
\hline & Splicing & $\mathrm{TT}$ & $10(9.8)$ & $2(2.8)$ & 0.15 & $4.50(0.94,21.6)$ & $4.99(1.00,25.00)$ & 0.0605 & \\
\hline & (ESE, ESS) & $\geq 1 \mathrm{~T}$ allele & $52(51.0)$ & $27(38.0)$ & 0.54 & $1.70(0.92,3.14)$ & $1.90(0.97,3.75)$ & 0.0936 & \\
\hline & Ala428Thr & $\mathrm{TT}$ vs $(\mathrm{CT}+\mathrm{TT})$ & & & & $3.75(0.80,17.66)$ & $3.96(0.81,19.3)$ & 0.0947 & \\
\hline
\end{tabular}

AA, African-American/African ancestry; OR, unadjusted odds ratio; Adj OR, adjusted odds ratio; $\mathrm{Cl}$, confidence interval.

microbial nucleic acid recognition, intracellular signaling, and/or endosomal/lysosomal processing and degradation.

The IRAK4 rs4251545 SNP codes for an Ala to Thr amino acid change at position 428 . This non-synonymous mutation introduces a potential Ser/Thr kinase target and presents a bulkier and more polar residue. Further, the IRAK4 rs4251545 locus occurs in an enhancer/silencer region of the gene, raising the additional possibility that this SNP may influence IRAK4 transcription levels.

\section{IMPACT OF IRAK4 rs4251545 ON SUBDOMAIN CONFORMATION}

In order to investigate the biochemical impact of the IRAK4 rs4251545 locus on the aforementioned disease states, we first noted the location of the missense mutation coded by this SNP in the context of the IRAK4 protein. The most definitive structural data that includes amino acid 428 (coded by IRAK4 rs4251545) is derived from $\mathrm{x}$-ray diffraction of tetrameric crystals of the inhibitor-bound IRAK4 kinase domain (amino acid residues 160460) (26). Figure 2 illustrates the IRAK4 kinase domain monomer in the context of the tetrameric crystal; amino acid 428 is represented in mauve, key residues of the activation loop are coded red, and key residues of the active binding site pocket are keyed green. We observed that amino acid 428 is located near the center of the penultimate $\alpha$ I helix on the surface of the truncated protein and faces the adjacent and almost parallel carboxy terminal $\alpha$ helix, $\alpha$ J. We refer to the subdomain in which the IRAK4 rs4251545 polymorphism resides as the extreme carboxy terminus (XCT). Specifically, the XCT, depicted in yellow within Figure 2, encompasses amino acid residues from approximately 418-460 and is comprised of the two carboxy terminal $\alpha$ helices ( $\alpha \mathrm{I}$ and $\alpha \mathrm{J}$ ) and a putative $3 / 10$ helix (with fewer residues per turn than the traditional $\alpha$ helix).

We performed MD simulations of the Ala428Thr variant to examine the impact of the IRAK4 rs4251545 coded missense mutation on local XCT conformation at the surface of the IRAK4 kinase domain. Superposition of the wild-type Ala 428 and variant Thr 428 structures with respect to the backbone atoms of $\alpha \mathrm{I}$ and the underlying $\alpha \mathrm{G}$ and $\alpha \mathrm{E}$ helices in dark blue, deep to $\alpha \mathrm{I}$ and $\alpha \mathrm{J}$, respectively, suggested differences in inter- and intrahelical dynamics between wild-type IRAK4 rs4251545 Ala and variant Thr alleles. Specifically, the Thr 428 variant enhances the $\mathrm{H}$-bonding capabilities of $\alpha \mathrm{I}$ and $\alpha \mathrm{J}$, stabilizing them both. Replacing Thr for Ala also expands the inter-helical distance between $\alpha \mathrm{I}$ and $\alpha$, increasing the size of the groove between them.

\section{DISCUSSION}

Dysregulation of and genetic alterations in inflammation and immune response pathways have been linked with cancer susceptibility $(6-9,28)$. Although African-American women suffer disproportionately from more deadly forms of $\mathrm{BrCa}$, only one study has explored the involvement of a single TLR-associated SNP (TLR1/TLR6/TLR10 rs7696175) in relation to BrCa among this high risk sub-group (19). To explore whether other genetic susceptibilities in the TLR-pathway play a role in BrCa among African-American women, we examined 16 SNPs from 10 TLRpathway genes in a pilot case-control study. We found that the TLR3 rs10025405 and IRAK4 rs4251545 loci under the additive genetic models were associated with significant alterations in $\mathrm{BrCa}$ risk among African-American women. 


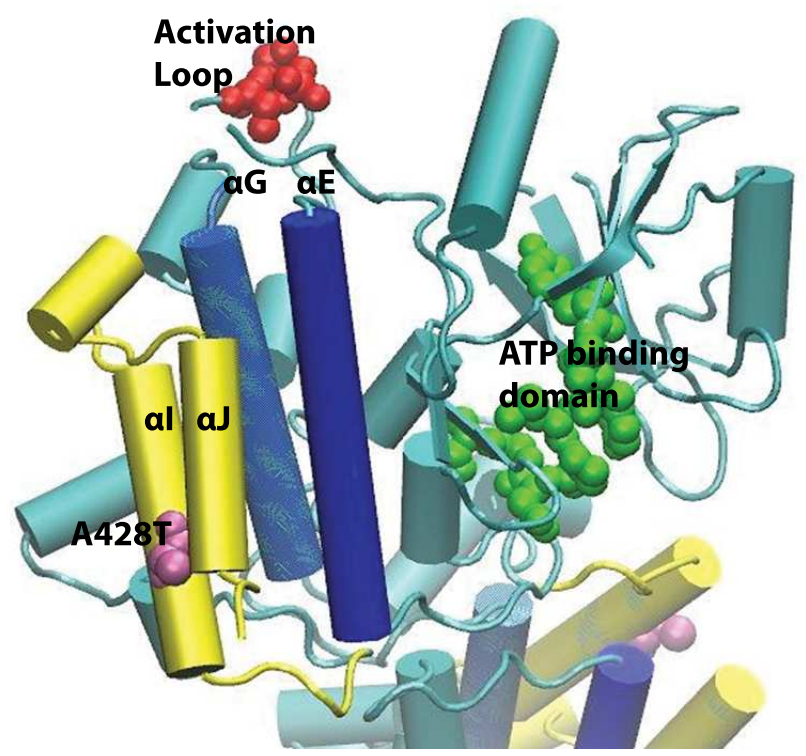

FIGURE 2 | Structural features of the IRAK4 kinase domain. The Ala428Thr (mauve) non-synonymous SNP is located on $\alpha$, the penultimate alpha helix, facing the carboxy terminal $\alpha \mathrm{J}$ as part of the putative extreme carboxy terminal (XCT) subdomain (yellow). Preliminary molecular dynamics simulations superpositioned backbone atoms of $\alpha \mathrm{l}$ (yellow), $\alpha \mathrm{G}$ (blue), and $\alpha E$ (blue) to evaluate local structural changes introduced by replacing Ala428 with Thr. The location of key residues in known functional domains, including Thr342, Thr345, and S346 of the activation loop (red) and amino acids 262 through 269 in the ATP binding domain (green) are also indicated.

\section{TLR3}

Inheritance of the homozygous minor TLR3 rs10025405 G allele was associated with a fivefold reduction in BrCa risk. While the location of this SNP in the $3^{\prime}$ flanking region may alter mRNA expression/processing or gene product function (e.g., anti-tumor response, cell death), to our knowledge there are no published reports on the relationship between this TLR3 SNP and human disease. However, there is direct and indirect pre-clinical as well as clinical evidence that TLR3 impacts breast tumor viability and/or behavior using TLR3-specific agonists, namely polyadenylic-polyuridylic acid [poly(A:U)] and polyinosinic-polycytidylic [poly(I:C)]. These agents are synthetic double-stranded RNA molecules that have been widely used as potent adjuvants in cancer immunotherapy, based on their ability to promote antigen-specific Th1-anti-tumor immune responses and boost antibody production when administered with antigen in mice (29-31). Salaun et al. (32) found that poly(A:U) treatment reduced breast tumor burden in immune compromised SCID/NOD mice, suggesting that the anti-tumor effects of poly $(\mathrm{A}: \mathrm{U})$ is attributed to TLR3 expressed by breast tumors rather than immune cells. The use of poly $(\mathrm{A}: \mathrm{U})$ increased $\mathrm{BrCa}$ patient survival and reduced tumor metastasis in two randomized clinical trials $(33,34)$. In addition, poly $(A: U)$ specifically reduced metastatic relapse among patients who possessed TLR3 positive tumors in a recent European clinical trial (32). Consistent with this, treatment of three out of four human $\mathrm{BrCa}$ lines with poly(I:C) induced apoptosis in vitro (35), and poly(A:U) inhibited HCC1806 BrCa tumor growth in vitro and in vivo (32).

Given that tumor-expressed TLR3 appears to promote apoptosis in transformed breast epithelia, it is reasonable to speculate that the TLR3 rs10025405 variant (protective among the AfricanAmerican women in our pilot study) alters TLR3 expression. In addition, the mechanism of TLR3-triggered $\mathrm{BrCa}$ apoptosis also requires downstream signaling via TRIF/TRAM1 (MyD88independent) and IRAK4 in Cama-1 human BrCa cells (35-37). Interestingly, in these cells type I IFN enhanced but could not initiate apoptosis (35). Thus, even if the TLR3 rs10025405 minor variant alters TLR3 expression, other factors, such as those that influence TLR3 regulation, localization, and/or signaling pathways, are also likely to impact TLR3-triggered $\mathrm{BrCa}$ apoptosis.

\section{IRAK4}

This report also finds that the IRAK4 rs4251545 variant in the XCT subdomain of IRAK4 (amino acids 418-460) is associated with a fivefold increase in BrCa risk among African-American women. While the minor variant of this SNP has been associated with Gram-positive bacterial infections (38), this report is the first to correlate this or any IRAK4 polymorphism with BrCa risk. IRAK4 rs4251545 simultaneously impacts a putative enhancer/silencer site (and subsequent IRAK4 expression levels) and alters the amino acid sequence (and possibly IRAK4 structure, phosphorylation state, kinase activity, and/or protein-protein interactions). We can envision a variety of scenarios in which the IRAK4 rs4251545 minor variant might promote BrCa risk by altering the expression or phosphorylation state of IRAK4 or its interaction with upstream adaptors (like MyD88) and/or downstream kinases (like IRAK1 and IRAK2) and E3 ubiquitin ligases (like TRAF6). Given our data on TLR3, it is also possible IRAK4 rs4251545 impairs TLR3-mediated apoptotic signaling and aids the survival of transformed breast epithelia. IRAK4 was first observed in the serum of both normal individuals and those with renal carcinoma (39). Further, host peptides corresponding to the IRAK4 XCT (aa 417441) were isolated from the serum of MCF7 BrCa xenografted mice (40). These findings prompt intriguing questions about the biological impact of IRAK4 trafficking and processing and the role of the XCT fragment.

The association of IRAK4 with BrCa risk in African-American women is not unexpected. Given that IRAK4 is a common mediator of TLR signaling from the cell surface and from endosomes (Figure 1), the fact that all TLRs except TLR8 have been shown to influence BrCa progression (9) implicates IRAK4 as an accomplice. Figure 1 illustrates representative signaling pathways from surface (TLR2 and TLR4) and endosomal (TLR3 and TLR4) TLRs [reviewed in Ref. (41)] that converge at IRAK4. It is wellknown that IRAK4 is activated by upstream signaling adaptor MyD88 docking via their shared death domains and complexes with IRAK1 to activate downstream E3 ubiquitin ligase TRAF6. However, it should be noted that TLR-pathway linked IRAK4 responds to both MyD88-dependent and -independent upstream signals and prompts both TRAF6-dependent and -independent downstream signaling $(35,42)$. As shown in Figure 1, IRAK4 mediated signaling results in a wide range of cancer-related cellular 
responses, including: imbalances in cell survival/cell death; production of pro-inflammatory cytokines and chemokines; expression of interferons and interferon-inducible genes; and release of matrix metalloproteinases that degrade extracellular matrix and facilitate cell migration/metastasis.

\section{STRENGTHS, LIMITATIONS AND FUTURE DIRECTIONS}

This report is only the second of its kind to describe the impact of innate immunity sequence variants on BrCa risk among AfricanAmerican women. Under the additive genetic model, we observed significant alterations in the risk estimates among carriers of the TLR3 rs10025405 and IRAK4 rs4251545 variant alleles, despite the use of individuals with benign disease as controls. However, if disease-free individuals had served as controls, the observed risk estimates for the TLR3 and IRAK4 loci would have been even more extreme, since disease-free individuals would be expected to have a smaller tendency to develop BrCa than individuals with benign nodules. In other words, the difference in risk between benign controls and $\mathrm{BrCa}$ patients is smaller than the difference in risk between disease-free controls and $\mathrm{BrCa}$ patients. While the risk estimates were not adjusted for population admixture, which is a common issue among African-Americans, several genetic epidemiology studies indicate that adjustment for population stratification only results in a \pm 0.02 change in the risk estimates relative to unadjusted models $(28,43-47)$. Despite the large differences in age between cases and controls, we did not observe significant variations in the risk estimates comparing age-adjusted and unadjusted risk estimates.

A variety of factors may confound the relationship between variant innate immunity markers and $\mathrm{BrCa}$. In order for a factor to serve as a confounder, it must be related to $\mathrm{BrCa}$ risk and the expression or function of the innate immunity markers. It is common knowledge that the risk of developing $\mathrm{BrCa}$ increases with long-term exposure to estrogen due to late age at menopause, late age at first birth, null parity, overweight/obesity, use of oral contraceptives, and use of hormone replacement therapy. In addition, there are limited published reports that suggest exposure to estrogen may alter the production of inflammatory mediators and cytokines via activation of TLR3 and TLR4 (48, 49). Consequently, the aforementioned reproductive/weight risk factors may in fact alter the inflammatory response activities of TLR3 and IRAK4. Unfortunately, we failed to adjust our risk estimates for these two factors and did not acquire this information from study participants. However, we have considered how our risk estimates may have varied if they had been adjusted for the aforementioned potential confounders. Following adjustment for surrogates of long-term estrogen exposure, we would predict an increase in BrCa risk estimates for the TLR3 and IRAK4 loci when compared to unadjusted models, based on the observation that long-term estrogen exposure enhances the production of inflammatory mediators in response to TLR4 (and downstream IRAK4) activation. Specifically, chronic estrogen exposure promotes TLR4-induced pro-inflammatory mediator production (IL-1- $\beta$, IL6, TNF- $\alpha$ ) in macrophages in vivo (48). In contrast, short-term estrogen exposure elicits an anti-inflammatory response via TLR3, suggesting a corresponding decrease in $\mathrm{BrCa}$ risk (49). Interestingly, short-term exposure to estrogen (i.e., 17 $\beta$-estradiol) does not influence TLR3 mRNA/protein expression in endometrial cell lines, but modulates TLR3 function by suppressing TLR3-ligand induced cytokine/chemokine production (49). Clearly, additional studies are needed to address the important question of whether long-term estrogen exposure influences TLR3 or IRAK4 expression or function in in vitro and in vivo $\mathrm{BrCa}$ models.

Due to our limited sample size, we did not have ample statistical power to assess whether the risk of developing $\mathrm{BrCa}$ would vary according to disease severity (i.e., high tumor stage, tumor size $\geq 2 \mathrm{~cm}$, invasive pathology, and triple negative $\mathrm{BrCa}$ ). In an exploratory analysis of the current study, innate immunity sequence variants [IRAK2 (rs242724, rs6442161), IRAK4 rs4251545), OAS1 rs10774671, CD14 rs2569188, and TLR4 (rs913930, rs7045953)] were significantly related to disease aggressiveness. For instance, IRAK4 rs4251545 was associated with a 2.56 -fold increase in invasive disease $(\mathrm{OR}=2.56$; $95 \% \mathrm{CI}=1.1-$ 5.91); whereas, inheritance of the IRAK2 rs242724 minor alleles were linked to non-aggressive disease (i.e., tumor size $<2 \mathrm{~cm}$, $\mathrm{ER}+/ \mathrm{PR}+/$ Her-2 neu+ status $)$.

From a statistical point of view, our results can only be considered suggestive and will require additional evaluation and validation in larger multi-center studies. Nevertheless, the potential biological and clinical implications are compelling. In this context, future studies will include sequencing of innate immunity genes, including TLR3 and IRAK4, as well as genes that directly or indirectly interact with these two markers. Such an approach will allow us to identify, evaluate and validate biomarkers of innate immunity that may ultimately serve as potential diagnostic, prognostic, and/or clinical management tools. Such efforts are likely to provide further understanding of the consequences of altered innate immunity on $\mathrm{BrCa}$ tumor progression. Functional studies are also needed to determine whether genetic changes in the putative enhancer/silencer site of the IRAK4 gene and/or structural changes in IRAK4 due to the Ala248Thr missense mutation alter the stability, activity, and/or proteinprotein interactions of this regulatory kinase. Future studies will also address downstream effects of TLR3 and IRAK4 alterations on immune/inflammatory responses and tumor behavior using in vitro and in vivo models. Currently, our laboratory is developing and exploring the effects of strategically designed IRAK4 agonists and antagonists on the behavior of transformed breast epithelia.

\section{CONCLUSION}

Our findings suggest that two mediators of innate immunity signaling, TLR3 and IRAK4, may impact BrCa development among African-American women. However, our results are preliminary and require further evaluation in larger, ethnically diverse populations.

\section{ACKNOWLEDGMENTS}

This research would not have been possible without the voluntary participation of women of African descent who were willing to help us better understand the impact of the innate immune system on $\mathrm{BrCa}$. We appreciate the support of the Emory Biomarker Service Center, Winship Cancer Institute for 
SNPStream allelic discrimination of innate immunity sequence variants. This research was supported by the JGBCC Bucks for Brains "Our Highest Potential" in Cancer Research Endowment to LaCreis R. Kidd, Avon Foundation (Emory), Sindab Foundation, Emory P60MD000525, UofL and NIEHS T32 ES011564, and P20-MD000175 NIH NCMHD to K. Sean Kimbro.

\section{REFERENCES}

1. Schwartz GF, Hughes KS, Lynch HT, Fabian CJ, Fentiman IS, Robson $\mathrm{ME}$, et al. Proceedings of the international consensus conference on breast cancer risk, genetics, \& risk management, April, 2007. Cancer (2008) 113:2627-37. doi:10.1002/ cncr. 23903

2. Njiaju UO, Olopade OI. Genetic determinants of breast cancer risk: a review of current literature and issues pertaining to clinical application. Breast J (2012) 18:436-42. doi: 10.1111/j.1524-4741.2012.01274.x

3. Grivennikov SI, Greten FR, Karin M. Immunity, inflammation, and cancer. Cell (2010) 140:883-99. doi:10. 1016/j.cell.2010.01.025

4. Hanahan D, Weinberg RA. Hallmarks of cancer: the next generation. Cell (2011) 144:646-74. doi: 10.1016/j.cell.2011.02.013

5. Ishii KJ, Koyama S, Nakagawa A, Coban C, Akira S. Host innate immune receptors and beyond: making sense of microbial infections. Cell Host Microbe (2008) 3:352-63. doi:10.1016/j.chom.2008. 05.003

6. Atkinson TJ. Toll-like receptors, transduction-effector pathways, and disease diversity: evidence of an immunobiological paradigm explaining all human illness? Int Rev Immunol (2008) 27:255-81. doi:10.1080/08830180801959072

7. Chen R, Alvero AB, Silasi DA, Steffensen KD, Mor G. Cancers take their Toll - the function and regulation of Toll-like receptors in cancer cells. Oncogene (2008) 27:225-33. doi:10.1038/sj.onc. 1210907

8. Rakoff-Nahoum S, Medzhitov R. Toll-like receptors and cancer. Nat Rev Cancer (2009) 9:57-63. doi:10. $1038 / \mathrm{nrc} 2541$

9. Kidd LR, Rogers EN, Yeyeodu ST, Jones DZ, Kimbro KS. Contribution of toll-like receptor signaling pathways to breast tumorigenesis and treatment. Breast Cancer Targets Ther (2013) 2013:43-51. doi:10. 2147/BCTT.S29172

10. Sato Y, Goto Y, Narita N, Hoon DSB. Cancer cell expressing Tolllike receptors and the tumor microenvironment. Cancer Microenviron (2009) 2:S205-14. doi:10.1007/s12307-009-0022-y

11. Demaria S, Pilones KA, Adams S. Cross-talk of breast cancer cells with the immune system. In: Gunduz
M, Gunduz E editors. Breast Cancer-Carcinogenesis, Cell Growth and Signalling Pathways. Rijeka, Croatia: InTech (2011). p. 457-82.

12. Xie W, Huang Y, Guo A, Wu W. Bacteria peptidoglycan promoted breast cancer cell invasiveness and adhesiveness by targeting toll-like receptor 2 in the cancer cells. PLoS ONE (2010) 5:e10850. doi:10.1371/ journal.pone.0010850

13. Yang H, Zhou H, Feng P, Zhou X, Wen H, Xie X, et al. Reduced expression of Toll-like receptor 4 inhibits human breast cancer cells proliferation and inflammatory cytokines secretion. J Exp Clin Cancer Res (2010) 29:92-9. doi:10.1186/17569966-29-92

14. Kang S-J, Tak J-H, Cho J-H, Lee H-J, Jung Y-J. Stimulation of the endosomal TLR pathway enhances autophagy-induced cell death in radiotherapy of breast cancer. Genes Genomics (2010) 32:599-606. doi:10.1007/s13258010-0139-x

15. Cai Z, Sanchez A, Shi Z, Zhang T, Liu M, Zhang D. Activation of Toll-like receptor 5 on breast cancer cells by flagellin suppresses cell proliferation and tumor growth. Cancer Res (2011) 71:2466-75. doi:10.1158/0008-5472.CAN-101993

16. Qiu J, Wang X, Guo X, Zhao C, Wu X, Zhang Y. Toll-like receptor 9 agonist inhibits ERalpha-mediated transactivation by activating NFkappaB in breast cancer cell lines. Oncol Rep (2009) 22:935-41. doi:10. 3892 /or 00000520

17. Lee JY, Park AK, Lee KM, Park SK, Han S, Han W, et al. Candidate gene approach evaluates association between innate immunity genes and breast cancer risk in Korean women. Carcinogenesis (2009) 30:1528-31. doi:10.1093/carcin/bgp084

18. Theodoropoulos GE, Saridakis V, Karantanos T, Michalopoulos NV, Zagouri F, Kontogianni P, et al. Toll-like receptors gene polymorphisms may confer increased susceptibility to breast cancer development. Breast (2012) 21:534-8. doi: 10.1016/j.breast.2012.04.001

19. Barnholtz-Sloan JS, Shetty PB, Guan X, Nyante SJ, Luo J, Brennan DJ, et al. FGFR2 and other loci identified in genome-wide association studies are associated with breast cancer in African-American and younger women. Carcinogenesis (2010) 31:1417-23. doi:10.1093/ carcin/bgq128

20. Carey LA, Perou CM, Livasy CA Dressler LG, Cowan D, Conway $\mathrm{K}$, et al. Race, breast cancer subtypes, and survival in the Carolina Breast Cancer Study. JAMA (2006) 295:2492-502. doi:10.1001/ jama.295.21.2492

21. Stark A, Kleer CG, Martin I, Awuah B, Nsiah-Asare A, Takyi V, et al. African ancestry and higher prevalence of triple-negative breast cancer: findings from an international study. Cancer (2010) 116:4926-32. doi:10.1002/cncr.25276

22. Hayanga AJ, Newman LA. Investigating the phenotypes and genotypes of breast cancer in women with African ancestry: the need for more genetic epidemiology. Surg Clin North Am (2007) 87:551-68. doi:10.1016/j.suc.2007. 01.003

23. Lund MJ, Butler EN, Bumpers HL, Okoli J, Rizzo M, Hatchett N, et al. High prevalence of triple-negative tumors in an urban cancer center. Cancer (2008) 113:608-15. doi:10. 1002/cncr.23569

24. Sherry ST, Ward MH, Kholodov M, Baker J, Phan L, Smigielski EM, et al. dbSNP: the NCBI database of genetic variation. Nucleic Acids Res (2001) 29:308-11. doi:10.1093/nar/ 29.1.308

25. Shim JY. Transmembrane helical domain of the cannabinoid CB1 receptor. Biophys J (2009) 96:3251-62. doi:10.1016/j.bpj.2008. 12.3934

26. Kuglstatter A, Villaseñor AG, Shaw $D$, Lee SW, Tsing S, Niu L, et al. Cutting Edge: IL-1 receptorassociated kinase 4 structures reveal novel features and multiple conformations. J Immunol (2007) 178:2641-5.

27. Essmann U, Perera L, Berkowitz ML, Darden T, Lee H, Pedersen LH, et al. A smooth Particle Mesh Ewald method. J Chem Phys (1995) 103:8577-93. doi:10.1063/1. 470117

28. Kidd LR, Jones DZ, Rogers EN, Beache S, Rudd JE, Ragin C, et al. Chemokine ligand 5 (CCL5) and chemokine receptor (CCR5) genetic variants and prostate cancer risk among men of African descent: a case-control study. Hered Cancer
Clin Pract (2012) 10:16-27. doi:10. 1186/1897-4287-10-16

29. Wang L, Smith D, Bot S, Dellamary L, Bloom A, Bot A. Noncoding RNA danger motifs bridge innate and adaptive immunity and are potent adjuvants for vaccination. J Clin Invest (2002) 110:1175-84. doi:10. 1172/JCI15536

30. Goutagny N, Estornes Y, Hasan U, Lebecque S, Caux C. Targeting pattern recognition receptors in cancer immunotherapy. Target Oncol (2012) 7:29-54. doi:10.1007/ s11523-012-0213-1

31. He H, Genovese KJ, Swaggerty CL, MacKinnon KM, Kogut MH. Co-stimulation with TLR3 and TLR21 ligands synergistically upregulates Th1-cytokine IFN- $\gamma$ and regulatory cytokine IL-10 expression in chicken monocytes. Dev Comp Immunol (2012) 36:756-60. doi:10.1016/j.dci.2011.11.006

32. Salaun B, Zitvogel L, Asselin-Paturel C, Morel Y, Chemin K, Dubois C, et al. TLR3 as a biomarker for the therapeutic efficacy of doublestranded RNA in breast cancer. Cancer Res (2011) 71:1607-14. doi:10.1158/0008-5472.CAN-103490

33. Lacour J, Lacour F, Ducot B, Spira A, Michelson M, Petit JY, et al. Polyadenylic-polyuridylic acid as adjuvant in the treatment of operable breast cancer: recent results. Eur J Surg Oncol (1988) 14:311-6.

34. Laplanche A, Alzieu L, Delozier T, Berlie J, Veyret C, Pargeot P, et al. Polyadenylic-polyuridylic acid plus locoregionl radiotherapy versus chemotherapy with CMF in operable breast cancer: a 14 year follow-up analysis of a randomized trial of the Federation Nationale des Centres de Lutte Contre le Cancer (FNCLCC). Breast Cancer Res Treat (2000) 64:189-91. doi:10.1023/A: 1006498121628

35. Salaun B, Coste I, Rissoan MC, Lebecque SJ, Renno T. TLR3 can directly trigger apoptosis in human cancer cells. J Immunol (2006) 176:4894-901.

36. Oshiumi H, Matsumoto M, Funami K, Akazawa T, Seya T. TICAM1 , an adaptor molecule that participates in Toll-like receptor 3mediated interferon- $\beta$ induction. Nat Immunol (2003) 4:161-7. doi: $10.1038 /$ ni886 
37. Kagan JC, Su T, Horng T, Chow A, Akira S, Medzhitov R. TRAM couples endocytosis of Toll-like receptor 4 to the induction of interferon$\beta$. Nat Immunol (2008) 9:361-8. doi:10.1038/ni1569

38. Sutherland AM, Walley KR, Nakada TA, Sham AH, Wurfel MM, Russell JA. A nonsynonymous polymorphism of IRAK4 associated with increased prevalence of grampositive infection and decreased response to toll-like receptor ligands. J Innate Immun (2011) 3:447-58. doi:10.1159/000323880

39. Scanlan MJ, Gordan JD, Williamson B, Stockert E, Bander NH, Jongeneel $\mathrm{V}$, et al. Antigens recognized by autologous antibody in patients with renal-cell carcinoma. Int $J$ Cancer (1999) 83:456-64. doi:10. 1002/(SICI)1097-0215(19991112) 83:4<456::AID-IJC4>3.0.CO;2-5

40. Orazine CI, Hincapie M, Hancock WS, Hattersley M, Hanke JH. A proteomic analysis of the plasma glycoproteins of a MCF-7 mouse xenograft: a model system for the detection of tumor markers. J Proteome Res (2008) 7:1542-54. doi:10. $1021 /$ pr7008516

41. McGettrick AF, O’Neill LA. Localisation and trafficking of Tolllike receptors: an important mode of regulation. Curr Opin Immunol (2010) 22:20-7. doi:10.1016/j.coi. 2009.12.002

42. Suzuki N, Suzuki S, Yeh WC. IRAK-4 as the central TIR signaling mediator in innate immunity. Trends Immunol (2002) 23:503-6. doi:10.1016/S1471-4906(02) 02298-6

43. Lavender NA, Benford ML, VanCleave TT, Brock GN, Kittles $\mathrm{RA}$, Moore $\mathrm{JH}$, et al. Examination of polymorphic glutathione Stransferase (GST) genes, tobacco smoking and prostate cancer risk among men of African descent: a case-control study. BMC Cancer (2009) 9:397. doi:10.1186/14712407-9-397

44. Benford ML, VanCleave TT, Lavender NA, Kittles RA, Kidd LR. 8q24 Sequence variants in relation to prostate cancer risk among men of African descent: a case-control study. BMC Cancer (2010) 10:334. doi:10.1186/1471-2407-10-334

45. VanCleave TT, Moore JH, Benford ML, Brock GN, Kalbfleisch T, Baumgartner RN, et al. Interaction among variant vascular endothelial growth factor (VEGF) and its receptor in relation to prostate cancer risk. Prostate (2010) 70:341-52. doi:10. 1002/pros.21067
46. Kidd LC, Vancleave TT, Doll MA, Srivastava DS, Thacker B, Komolafe $\mathrm{O}$, et al. No association between variant $\mathrm{N}$-acetyltransferase genes, cigarette smoking and prostate cancer susceptibility among men of African descent. Biomark Cancer (2011) 2011:1-13. doi:10.4137/BIC S6111

47. Chang BL, Spangler E, Gallagher S, Haiman CA, Henderson B, Isaacs $\mathrm{W}$, et al. Validation of genomewide prostate cancer associations in men of African descent. Cancer Epidemiol Biomarkers Prev (2011) 20:23-32. doi:10.1158/1055-9965. EPI-10-0698

48. Calippe B, Douin-Echinard V, Delpy L, Laffargue $M$, Lélu K, Krust A, et al. 17Beta-estradiol promotes TLR4-triggered proinflammatory mediator production through direct estrogen receptor alpha signaling in macrophages in vivo. J Immunol (2010) 185: 1169-76. doi:10.4049/jimmunol. 0902383

49. Lesmeister M, Jorgenson R, Young S, Misfeldt M. 17Beta-estradiol suppresses TLR3-induced cytokine and chemokine production in endometrial epithelial cells. Reprod Bio Endocrinol (2005) 3:74. doi:10. 1186/1477-7827-3-74
Conflict of Interest Statement: The authors declare that the research was conducted in the absence of any commercial or financial relationships that could be construed as a potential conflict of interest.

Received: 23 July 2013; accepted: 03 October 2013; published online: 29 October 2013.

Citation: Yeyeodu ST, Kidd LR, OpreaIlies GM, Burns BG, VanCleave TT, Shim $J-Y$ and Kimbro KS (2013) IRAK4 and TLR3 sequence variants may alter breast cancer risk among African-American women. Front. Immunol. 4:338. doi: 10.3389/fimmu.2013.00338

This article was submitted to Molecular Innate Immunity, a section of the journal Frontiers in Immunology.

Copyright (C) 2013 Yeyeodu, Kidd, OpreaIlies, Burns, VanCleave, Shim and Kimbro. This is an open-access article distributed under the terms of the Creative Commons Attribution License (CC BY). The use, distribution or reproduction in other forums is permitted, provided the original author(s) or licensor are credited and that the original publication in this journal is cited, in accordance with accepted academic practice. No use, distribution or reproduction is permitted which does not comply with these terms. 